\title{
Seasonal variation in the necropsy incidence of massive pulmonary embolism
}

\author{
J Green, C Edwards
}

\begin{abstract}
Aims-To investigate the seasonal incidence of massive pulmonary embolism at necropsy.

Methods-Massive pulmonary embolism was defined as a recent thromboembolus occluding the pulmonary trunk or one or both main pulmonary arteries and constituting the main cause of death. A total of 4289 necropsies carried out at East Birmingham Hospital from 1979 to 1988 was reviewed. The number of subjects with massive pulmonary embolism was noted and the accumulated percentage for each calendar month was calculated. Results-Massive pulmonary embolism was found in $13.02 \%$ of necropsies carried out in April; in September and October the percentage rose to 14.29 and $14 \cdot 19$, respectively, after falling to $8 \cdot 04$ and $\mathbf{7 . 8 0}$ in June and July. In January and February the incidence fell again to about $9 \%$.

Conclusions-The incidence of massive pulmonary embolism at East Birmingham Hospital is highest in the spring and autumn. Investigation of the seasonal incidence in arctic and tropical areas would be of interest.
\end{abstract}

(F Clin Pathol 1994;47:58-60)

Pulmonary embolism is a major cause of morbidity and mortality, accounting for up to $10 \%$ of postoperative deaths and around $10 \%$ of deaths overall. ${ }^{1-3}$ Age, heart disease, malignancy, trauma and recent surgery are well established predisposing factors, ${ }^{145}$ while the influence of gender remains controversial. ${ }^{134}$

For some considerable time it has been apparent to us that the incidence of massive pulmonary embolism at necropsy is variable. Weeks or even months may go by without encountering a single case, and then quite suddenly virtually every patient will exhibit one or other sign of pulmonary embolic disease. Because it seemed possible that the increased morbidity associated with cold weather may also have been a pathogenic fac- tor, the seasonal incidence of this condition was investigated.

\section{Methods}

The study was based on the necropsy records of East Birmingham Hospital for the 10 years from 1979 to 1988 . East Birmingham is a district general hospital, situated on the east side of the Birmingham and Wolverhampton industrial conurbation. It houses general medical, general surgical, orthopaedic and geriatric units, and specialist units of thoracic surgery, thoracic medicine, cardiology, infectious disease and renal dialysis. Until 1992 there were no obstetric or gynaecological beds, and cardiac surgery and neurosurgery have always been carried out elsewhere in the city.

At East Birmingham, most patients coming to necropsy have died in the hospital. Subjects "brought in dead" to the accident unit are transferred to the public mortuary in accordance with the policy of the city Coroner. Recently, this policy has been extended to include a significant proportion of inpatient deaths, so that current necropsy data are not comparable with those of previous years. For this reason the December 1988 cutoff point was chosen.

For the purposes of this study, a massive pulmonary embolus was defined as recent adherent or non-adherent thromboembolus, situated either in the pulmonary trunk or in one or both main pulmonary arteries, and constituting the main cause of death. Subjects with thromboemboli in second order or smaller arteries were excluded, as were those with infarction alone. No attempt was made to assign patients to "medical", "surgical", or other categories.

For each calendar month, the total number of necropsies and the number with massive pulmonary emboli were noted. Monthly variation was investigated by arranging the data into 12 groups corresponding to the calendar months. Each group consisted of the total number of necropsies carried out in that specific month over the 10 year period, together with the number and percentage of subjects with massive pulmonary emboli (table).
Department of Histopathology, East Birmingham Hospital, Bordesley Green East, Birmingham B9 5SS J Green C Edwards

Correspondence to: Dr C Edwards Accepted for publication 29 July 1993
Monthly incidence of pulmonary emboli at East Birmingham Hospital, 1979-88

\begin{tabular}{|c|c|c|c|c|c|c|c|c|c|c|c|c|}
\hline & $\exists A N$ & $F E B$ & $M A R$ & $A P R$ & $M A Y$ & $\mathscr{f U N}$ & $\mathscr{f U L}$ & $A U G$ & $S E P$ & $O C T$ & NOV & $D E C$ \\
\hline \multirow{3}{*}{$\begin{array}{l}\text { No of necropsies } \\
\text { No of pulmonary } \\
\text { emboli } \\
\% \text { of pulmonary } \\
\text { emboli }\end{array}$} & 417 & 361 & 421 & 384 & 368 & 311 & 282 & 341 & 322 & 310 & 395 & 371 \\
\hline & 38 & 33 & 48 & 50 & 30 & 25 & 22 & 41 & 46 & 44 & 44 & 43 \\
\hline & $9 \cdot 11$ & $9 \cdot 14$ & 11.40 & 13.02 & $8 \cdot 15$ & 8.04 & $7 \cdot 80$ & 12.02 & $14 \cdot 29$ & $14 \cdot 19$ & $11 \cdot 14$ & 11.59 \\
\hline
\end{tabular}


The percentage of patients with massive pulmonary embolus in each month was compared with the percentage for the other 11 months using the formula for standard error of difference between percentages. ${ }^{6}$ Seasonal variation was investigated by comparing the figures for spring (March and April), summer (June and July), autumn (September and October) and winter (December and January), using the same method.

\section{Results}

In the 10 years studied, 4289 patients came to necropsy, with a more or less linear decrease in number per annum from 531 in 1979 to 335 in 1988 , a trend which still continues. Massive pulmonary embolus was found in $461(10.75 \%)$ cases. The annual percentage ranged from $9 \cdot 0$ to $12 \cdot 61$, but did not vary significantly (SD $1 \cdot 27)$.

The numbers of necropsies for each month of the 10 year period, together with the numbers and percentages of cases with massive pulmonary embolism, are shown in the table. The correlation between the percentage of cases with massive emboli and the month is shown in the figure.

The percentage of patients with massive pulmonary embolus varied between 14.29 in September to $7 \cdot 80$ in July, with a mean (SD $2 \cdot 58$ ) of $10 \cdot 74$. There seemed to be two peaks, one in April and the other in September and October. The peaks were separated by a trough, which consisted of the months of May, June, and July, where the incidence fell to about $8 \%$. Statistical analysis, however, showed that only the October percentage $(14 \cdot 19)$ was significantly different from the rest of the year $(p<0.05)$. The percentage for April (13.02), September (14.29), May $(8 \cdot 15)$ and July $(7 \cdot 8)$ just failed to achieve significance $(\mathrm{p}<0 \cdot 10)$.

Further analysis of the data showed that the incidence of pulmonary embolus in the summer months of June and July was significantly lower than in the rest of the year $(p<0.05)$, lower than the spring months of March and April $(\mathrm{p}<0.03)$, and lower than the autumn months of September and October $(p<0.001)$. The incidence in autumn was significantly higher than in the

Monthly variation in the percentage of necropsies with massive pulmonar embolism. winter months of December and January $(p<0.05)$, and significantly higher than in the rest of the year $(p<0.01)$.

Although significantly fewer necropsies were carried out in July $(p<0.05)$, there was no correlation between the number carried out and the percentage of cases with massive pulmonary embolism.

\section{Discussion}

At the start of this study, it was anticipated that there would be a peak in the winter months, in parallel with the seasonal increase in trauma and respiratory tract infection. The results, however, show that there are two peaks-one in the autumn and another in the spring.

The two peaks could be a reflection of the activity in the hospital over the year, with fewer complex cases being dealt with during the summer and Christmas holiday periods. Unfortunately, no data on the medical and surgical workload are available, but it is our impression that there is little if any change from month to month. East Birmingham is a district general hospital which deals, for the most part, with either emergency cases or patients with conditions such as malignancy or suspected malignancy requiring urgent investigation and treatment. "Cold" admissions from the surgical and medical waiting lists are fewer. Certainly, there was no correlation between the monthly total of necropsies and the incidence of pulmonary embolism.

There have been a few attempts to investigate the seasonal incidence of thromboembolic disease. Allen, in 1945, found that thrombotic disease was more common in the winter. ${ }^{7}$ By contrast, Scharnoff et $a l^{8}$ showed that in New York the spring and autumn were periods of high incidence and that winter and summer were periods of low incidence of thromboembolic disease. The shape of the graph they used to illustrate their paper is almost identical with ours. Both of these papers, however, were based on the overall incidence of thromboembolic disease, including pulmonary embolism or infarction, coronary artery thrombosis, myocardial infarction, mesenteric and cerebral thrombosis, and splenic and renal infarction. Scharnoff et al believed that the variation was due to thrombocytosis arising as a consequence of damage to megakaryocytes, occurring when periods of relative inactivity or immobility were followed by periods of resumed activity. Neither of these studies was corroborated by statistical analysis.

In a more recent paper, Putzke et $a l^{9}$ stated that pulmonary embolism in Rostock on the Baltic coast was more common during phases of fine weather in winter. These authors cited previous investigations published in the older German literature correlating pulmonary embolism with frontal systems, thunder, and the föhn, a warm wind which occurs in alpine areas. The authors were unable to confirm an association with weather fronts. 
Unfortunately, the paper contains no hard data, and the statistical analysis is described only in vague terms.

The reason for the increased incidence of massive pulmonary embolism in the spring and autumn is far from clear. There is, however, some indication from this and other studies that the weather may be a pathogenetic factor. Studies in arctic and tropical areas would be of interest,

We are grateful to Mrs Ruth Fry for her secretarial assistance in preparing this paper.

1 Coon WW. Risk factors in pulmonary embolism. Surg Gynecol Obstet 1976;143:385-90.
2 Rubinstein I, Murray D, Hoffstein V. Fatal pulmonary emboli in hospitalised patients. An autopsy study. Arch Intern Med 1988;148:1425-6.

3 Karwinski B, Svendsen E. Comparison of clinical and post mortem diagnosis of pulmonary embolism. F Clin Pathol 1989;42:135-9.

4 Hopkins NFG, Wolfe JHN. Thrombosis and pulmonary embolism. BMF 1991;303:1260-2.

5 Raskob GE, Hull RD. Diagnosis and management of pulmonary thromboembolism. $O \Im$ Med 1990;76:787-97.

6 Swinscow TDV. Statistics at square one. 8th Edn. London: British Medical Association, 1983.

7 Allen AW, Linton RR, Donaldson GA. Venous thrombosis and pulmonary embolism. $\mathscr{F} A M A$ 1945;128: 397-403.

8 Scharnoff JC, Rosenberg M, Mistica BA. Seasonal variation in fatal thromboembolism and its high incidence in the surgical patient. Surg Gymecol Obstet 1963;116: $11-14$

9 Putzke HP, Möbius C, Gunther U, Bargenda M, Dobberphul J. Zur Häufigkeit der tödlichen Lungenembolie unter besonderer Berucksichtigung von Grundleiden und Wettereinfluß. Z Gesamte Inn Med 1989;44:106-9. 